\title{
Efeitos de Doses Reduzidas de Fluazifop-P-Butil no Consórcio ENTRE SOJA E Brachiaria brizantha ${ }^{1}$
}

\author{
Effects of Reduced Rates of Fluazifop-P-Butyl on Soybean Intercropped With \\ Brachiaria brizantha
}

\author{
SILVA, A.C. ${ }^{2}$, FERREIRA, L.R. ${ }^{3}$, SILVA, A.A. ${ }^{4}$, PAIVA, T.W.B. ${ }^{5}$ e SEDIYAMA, C.S. ${ }^{6}$
}

\begin{abstract}
RESUMO - A integração agricultura-pecuária tem se tornado opção vantajosa, beneficiando simultaneamente a produção de grãos e a pecuária. Para viabilizar o consórcio entre culturas e forrageiras, é necessário o manejo adequado da forrageira, evitando-se a interferência negativa desta sobre a cultura. Objetivou-se neste trabalho avaliar os efeitos do fluazifop-pbutil no estabelecimento do consórcio entre soja e braquiária (Brachiaria brizantha). O experimento foi realizado em sistema de plantio direto, avaliando-se seis doses de fluazifopp-butil $\left(0,18,36,54,72\right.$ e $\left.90 \mathrm{~g} \mathrm{ha}^{-1}\right)$, aplicadas aos 21 e 28 dias após a emergência da soja (DAE), e duas testemunhas (soja e braquiária em monocultura e capinadas). Não houve interação entre doses e épocas de aplicação. Verificou-se que todas as doses do fluazifopp-butil reduziram a produção de biomassa da $B$. brizantha, exceto a dose de $18 \mathrm{~g} \mathrm{ha}^{-1}$, na aplicação precoce $(21 \mathrm{DAE})$. Em relação à soja, verificou-se maior altura das plantas e de inserção da primeira vagem no tratamento sem herbicida e na dose de $18 \mathrm{~g} \mathrm{ha}^{-1}$ de fluazifopp-butil. O estande final, o número de sementes por vagem e o peso de 100 sementes não foram influenciados pelos tratamentos. Para obter produção de grãos semelhante à da testemunha, foi necessário aplicar $54 \mathrm{~g} \mathrm{ha}^{-1}$ de fluazifop-p-butil aos $21 \mathrm{DAE}$ ou $36 \mathrm{~g} \mathrm{ha}^{-1}$ aos 28 DAE. O componente responsável pela redução na produção da soja foi o número de vagens, o qual seguiu a mesma tendência da produção, diferindo nos mesmos tratamentos em relação à testemunha.
\end{abstract}

Palavras-chave: Glycine max, manejo, integração agricultura-pecuária.

ABSTRACT - Crop-livestock integration has been an advantageous option, benefitting both grain and animal production. However, an adequate forage management to prevent its negative interference in the crop is an essential requirement for the success of the intercropping system. The objective of this work was to evaluate the effects of fluazifop-p-butyl on the establishment of soybean and Brachiaria brizantha intercropping. The experiment was carried out in Coimbra-MG, to evaluate 6 rates of fluazifop-p-butyl $\left(0,18,36,54,72\right.$ and $\left.90 \mathrm{~g} \mathrm{ha}^{-1}\right)$ applied at two timings (21 and 28 days after soybean emergence - DAE). Additionally, two control treatments were included (soybean and Brachiaria in monocrop kept clean by hand hoeing). The timing of application did not affect the efficacy of the herbicide doses. It was verified that doses of fluazifop-p-butyl reduced Brachiaria biomass, except the dose of $18 \mathrm{~g} \mathrm{ha}^{-1}$ at $21 \mathrm{DAE}$ and the treatment without herbicide. Higher final plant height and height of first pod insertion of soybean plants were observed in the treatment without herbicide and at the dose of $18 \mathrm{~g} \mathrm{ha}^{-1}$ of fluazifop-p-butyl. Final stand, number of seeds per pod and 100 seed weight were not affected by the treatments. To obtain soybean grain yield similar to the control it was necessary to apply $54 \mathrm{~g} \mathrm{ha}^{-1}$ of fluazifop-p-butyl at $21 \mathrm{DAE}$ or $36 \mathrm{~g} \mathrm{ha}^{-1}$ at $28 \mathrm{DAE}$. The component that contributed to reduce soybean grain yield was pod number per plant.

Key words: Glycine max, management, crop-livestock integration.

Recebido para publicação em 20.4.2004 e na forma revisada em 10.9.2004.

2 Doutoranda, Dep. de Fitotecnia da Universidade Federal de Viçosa - UFV, 36570-000 Viçosa-MG, <andreia@ vicosa.ufv.br>; ${ }^{3}$ Prof. Adjunto do Dep. de Fitotecnia da UFV, <lroberto@ ufv.br>; ${ }^{4}$ Prof. Adjunto do Dep. de Fitotecnia da UFV, <aasilva@ufv.br>; ${ }^{5}$ Acadêmico de Agronomia, estagiário do Dep. de Fitotecnia da UFV; ${ }^{6}$ Prof. Titular do Dep. de Fitotecnia da UFV, <csediyama@ufv.br>. 


\section{INTRODUÇÃO}

As explorações agrícola e pecuária no Brasil têm apresentado pouca sustentabilidade dos recursos naturais. Como conseqüência, têm-se observado a degradação de pastagens, a queda de produtividade das lavouras, o empobrecimento da fertilidade do solo, além da baixa retenção de água, a qual incrementa o processo erosivo (Kichel et al., 2000).

A integração agricultura-pecuária tem se tornado opção vantajosa, beneficiando duas atividades de importância econômica, a produção de grãos e a pecuária, proporcionando ganhos mútuos ao produtor (Salton et al., 2001). A rotação entre soja e pastagem (dois a três anos de soja e três anos de pastagem) tem propiciado benefícios para a cultura da soja e para a pastagem, como a diminuição da incidência de plantas daninhas e a quebra do ciclo de pragas e doenças da soja (cancro-da-haste, murcha, nematóides, etc.), resultando em aumento de produtividade (Kichel et al., 2000). O sistema radical das forrageiras explora volume maior de solo e recicla maior quantidade de nutrientes. Além disso, aumenta a atividade biológica do solo, favorece a elevação do teor de matéria orgânica e reduz a erosão (Salton et al., 2001). Ademais, as forrageiras do gênero Brachiaria são materiais de excelente qualidade para cobertura do solo no sistema de plantio direto.

O sistema de plantio direto tornou-se muito mais que um método de conservação do solo e tem contribuído para uma agricultura sustentável, mantendo-se alta produtividade com mínimo impacto ao meio ambiente (Amaral, 2001). No entanto, apesar de amplamente adotado, esse sistema de plantio dependerá, para sua evolução, de fontes eficientes de cobertura morta com longevidade adequada. Esta característica é oferecida pelas forrageiras do gênero Brachiaria, as quais têm produzido, quando bem manejadas, acima de $15 \mathrm{t} \mathrm{ha}^{-1}$ de biomassa seca, persistindo por mais de seis meses na superfície do solo (Cobucci, 2001).

Apesar da comprovada viabilidade técnicoeconômica do consórcio entre milho e braquiária na recuperação de pastagens degradadas (Carvalho et al., 1990; Portes et al., 2000), o consórcio entre soja e braquiária apresenta desafios, devido à menor capacidade competitiva da cultura com a forrageira, além da dificuldade na colheita da soja quando em consórcio. Segundo Cobucci (2001), o manejo da braquiária com uso de herbicidas ou plantio da braquiária em pós-emergência da cultura da soja, associado ao uso de variedades precoces de porte médio a alto e à maior altura de inserção da primeira vagem, poderão viabilizar o sistema. Nesse contexto, o objetivo deste trabalho foi avaliar o consórcio entre soja e braquiária, em função de doses do graminicida fluazifop-p-butil, aplicadas em dois estádios de desenvolvimento da soja, para o manejo de $B$. brizantha.

\section{MATERIAL E MÉTODOS}

O experimento foi instalado em campo, no ano agrícola 2002/2003, na Estação Experimental de Coimbra-MG, em solo classificado como Argissolo Vermelho-Amarelo Câmbico distrófico, fase terraço, cujas principais características físicas e químicas são: pH em água de 4,9; 3,11 dag $\mathrm{kg}^{-1}$ de matéria orgânica; V de 34\%; e teores de P, K, Zn, Fe, $\mathrm{Mn}, \mathrm{Cu}$ e B de 14,$8 ; 80,0 ; 2,2 ; 33,2 ; 27,6 ; 1,2$ e $0,37 \mathrm{mg} \mathrm{dm}^{-3}$ e de $\mathrm{Ca}, \mathrm{Mg}$ e $\mathrm{H}+\mathrm{Al}$ de 1,$4 ; 0,6$ e 4,29 de cmolc $\mathrm{dm}^{-3}$, respectivamente. A temperatura média, a umidade relativa e a precipitação pluvial referentes ao período de condução do ensaio são apresentadas na Figura 1.

O experimento foi implantado em sistema de plantio direto, após a dessecação química da cobertura vegetal composta por plantas daninhas (Andropogon bicornis, Artemisia verlotorum, Bidens pilosa, B. plantaginea Commelina benghalensis, Cynodon dactylon, Cyperus esculentus, Melinis minutiflora, Paspalum conjugatum, Raphanus raphanistrum e Sorghum arundinaceum).

A semeadura da soja (Glycine max cv. UFV-16) e da $B$. brizantha (cv. MG-5) foi realizada simultaneamente em 25/11/02, utilizando-se a semeadora Semeato previamente ajustada. O espaçamento utilizado foi de $0,55 \mathrm{~m}$ entre as linhas de soja, obtendose estande de 250.000 plantas ha ${ }^{-1}$, sendo a braquiária semeada entre as linhas da soja (6 kg ha ${ }^{-1}$ de sementes). A unidade experimental foi composta por uma área de $26,4 \mathrm{~m}^{2}$, 
sendo a área útil de $8,8 \mathrm{~m}^{2}$. Imediatamente antes da semeadura, as sementes de soja foram inoculadas com as estirpes SEMIA 587 e SEMIA 5019 de Bradyrhizobium japonicum. A adubação de plantio consistiu de $250 \mathrm{~kg} \mathrm{ha}^{-1}$ da formulação 8-28-16. Todos os tratos culturais e fitossanitários necessários foram realizados. No controle de plantas daninhas dicotiledôneas utilizou-se o fomesafen $\left(0,2 \mathrm{~kg} \mathrm{ha}^{-1}\right)$ em área total, aplicado aos 19 dias após a emergência da soja (DAE).

O delineamento experimental adotado foi o de blocos casualizados, com 14 tratamentos e quatro repetições, em arranjo fatorial $6 \times 2+2$, com seis doses de fluazifop-p-butil $(0,18,36$, 54,72 e $90 \mathrm{~g} \mathrm{ha}^{-1}$ ), aplicadas aos 21 e $28 \mathrm{DAE}$, e as testemunhas (braquiária e soja em monocultura e capinadas). O fluazifop-p-butil foi aplicado com pulverizador costal pressurizado com $\mathrm{CO}_{2}$, equipado com barra de quatro bicos TT1 10.02, espaçados de 0,5 m, à pressão constante de $2,0 \mathrm{kgf} \mathrm{cm}^{-2}$, aplicando-se o equivalente a $160 \mathrm{~L} \mathrm{ha}^{-1}$ de calda.

Aos 14 e 35 dias após a segunda época de aplicação do fluazifop-p-butil (42 e 63 DAE, respectivamente) foram realizadas amostragens da comunidade infestante, utilizando-se um quadrado de 0,5 m de lado, lançado aleatoriamente nas unidades experimentais. Todas as plantas daninhas coletadas foram identificadas e secas em estufa de circulação forçada de ar a $70{ }^{\circ} \mathrm{C}$, até atingir biomassa constante, para posterior determinação de biomassa seca.

O número de vagens por planta e de sementes por vagem e a altura das plantas e de inserção da primeira vagem foram determinados, por ocasião da colheita, no estádio R8 da soja, segundo escala de Fehr et al. (1971), em dez plantas amostradas na área útil da unidade experimental. A colheita da soja foi realizada manualmente, coletando-se todas as plantas da área útil. Determinaram-se o estande final e a produtividade da cultura, após correção do teor de umidade dos grãos para $13 \%$. O peso de 100 sementes foi obtido pela contagem e pesagem de uma amostra retirada do total de sementes colhidas na área útil da unidade experimental.

Após a colheita da soja, foram coletadas as plantas de $B$. brizantha em 1,0 m de linha dentro de cada unidade experimental, determinando-se posteriormente a biomassa seca total da parte aérea dessas plantas.

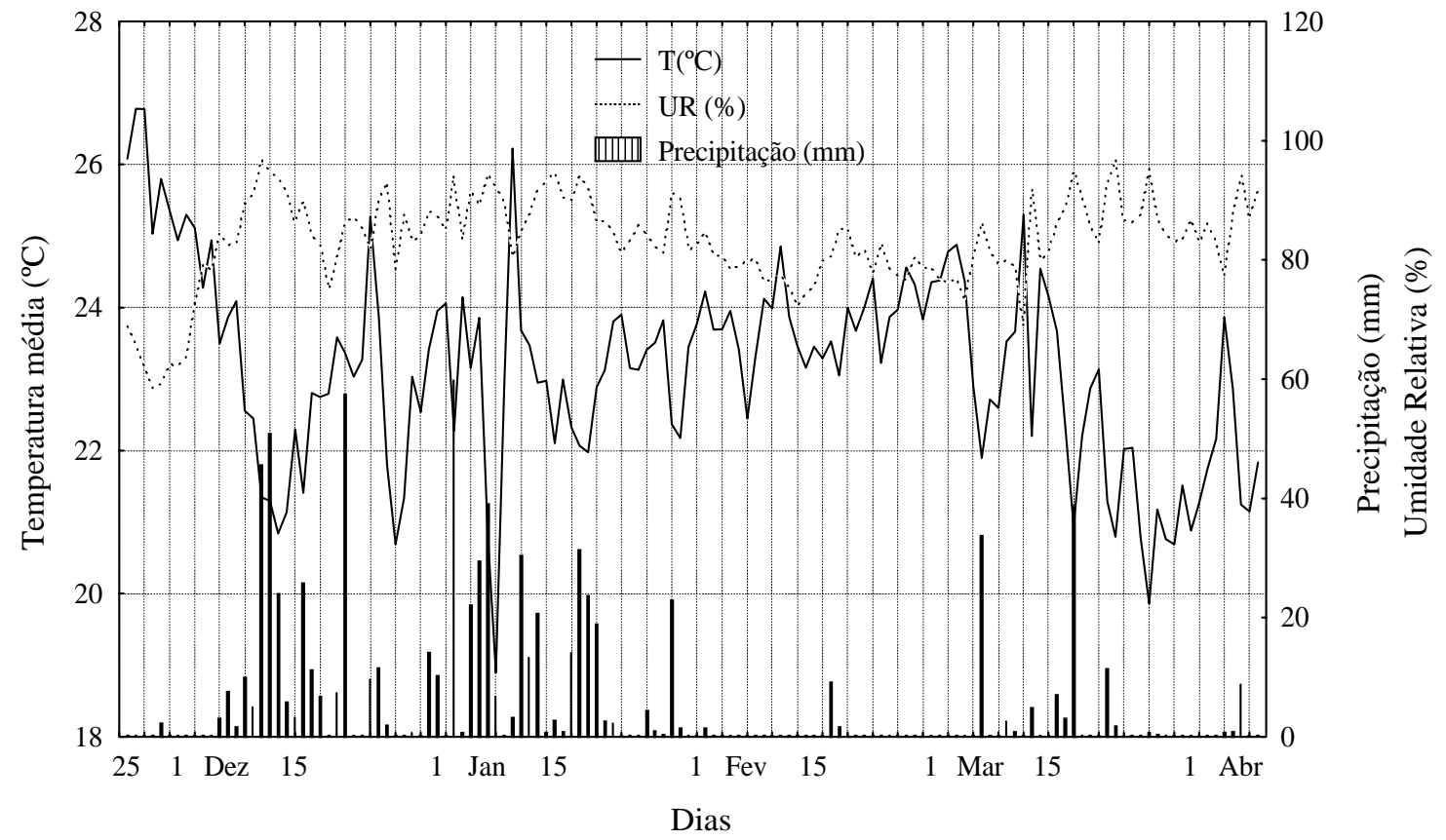

Figura 1 - Temperatura média, umidade relativa e precipitação pluvial, referentes ao período de condução do ensaio. 
Os dados obtidos foram submetidos à análise de variância, sendo aqueles referentes à biomassa seca da parte aérea da $B$. brizantha transformados para $\sqrt{\mathrm{x}+0,5}$ antes da análise. Nas estimativas dos parâmetros da regressão do modelo utilizou-se o programa SIGMAPLOT. Foram adotados os modelos log-logístico e logístico. O modelo log-logístico - equação 1 (Seefeldt et al., 1995) apresenta quatro parâmetros, em que $Y_{0}$ é o limite inferior; $a$ é a diferença entre o limite superior e o inferior; e $b$ descreve o declive da curva em torno de $I_{50}$ (concentração do produto que inibe 50\% do crescimento do bioindicador), que é dado pelo valor de $x_{0}$. O modelo logístico - equação 2 (Finney, 1979) possui três parâmetros: $a$ é denominado "nível de saturação"; $x_{0}$ é o ponto de inflexão da curva, que corresponde ao valor de $\mathrm{I}_{50}$; e $b$ descreve o declive da curva em torno de $I_{50}$.

$$
\begin{aligned}
& Y=Y_{0}+\frac{a}{1+\left(\frac{X}{x_{0}}\right)^{b}} \\
& Y=\frac{a}{1+\left(\frac{X}{x_{0}}\right)^{b}}
\end{aligned}
$$

Para comparar as médias dos tratamentos com as das testemunhas, foi utilizado o teste de Dunnett a 5\% de probabilidade.

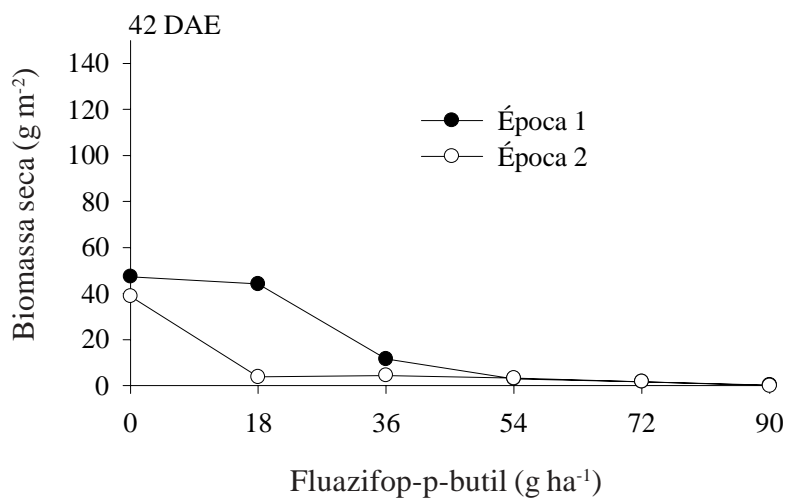

\section{RESULTADOS E DISCUSSÃO}

Não houve interação entre doses e épocas de aplicação do fluazifop-p-butil para as características avaliadas, indicando que a época de aplicação não interferiu na eficácia das doses.

As doses reduzidas do graminicida, cuja função foi paralisar o crescimento de $B$. brizantha, foram insuficientes para o controle das gramíneas infestantes, as quais representaram um problema ao sucesso do consórcio. Houve incremento da biomassa seca dessas plantas, constituída principalmente por B. plantaginea, no tratamento sem aplicação do fluazifop-p-butil e na menor dose. Todavia, verificou-se redução na biomassa seca dessas plantas à medida que a dose do fluazifop-p-butil foi aumentada. A aplicação na segunda época proporcionou melhor controle das gramíneas infestantes em relação à primeira época (Figura 2), possivelmente porque as gramíneas que emergiram após a primeira aplicação foram controladas, aliado ao fechamento da cultura logo em seguida, reduzindo a capacidade de recuperação dessas plantas.

Foram verificados efeitos de doses e épocas de aplicação do fluazifop-p-butil para a biomassa seca da parte aérea das plantas de B. brizantha. A aplicação aos $21 \mathrm{DAE}$ permitiu maior acúmulo de biomassa de $B$. brizantha em relação àquela feita aos $28 \mathrm{DAE}$. A maior eficiência do fluazifop-p-butil no controle de B. brizantha em aplicação mais tardia (28 DAE) deveu-se à germinação parcelada dessa

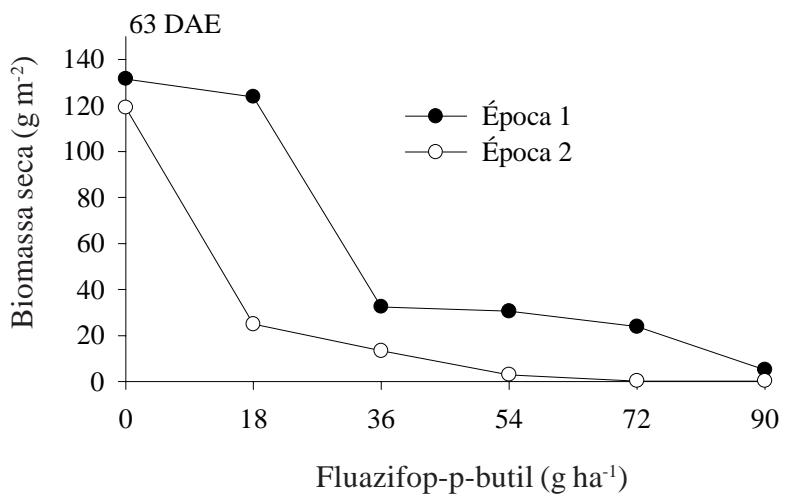

Figura 2 - Biomassa seca da parte aérea das gramíneas infestantes da área experimental, em função de doses de fluazifop-p-butil, em duas épocas de aplicação (21 e 28 DAE). 
espécie. Desse modo, as plantas que emergiram entre 21 e 28 DAE foram controladas pela segunda aplicação. Além disso, o intervalo para o fechamento da cultura foi mais rápido após a segunda época de aplicação, favorecendo o controle. A dose que promoveu 50\% de redução da biomassa de $B$. brizantha foi de $48,8 \mathrm{~g} \mathrm{ha}^{-1}$ (Figura 3). O tratamento sem herbicida e a dose de $18 \mathrm{~g} \mathrm{ha}^{-1}$, aplicada aos $21 \mathrm{DAE}$, não diferiram da $B$. brizantha em monocultivo. No entanto, na aplicação aos $28 \mathrm{DAE}$, nenhuma dose resultou em biomassa da $B$. brizantha semelhante à da testemunha, confirmando o efeito da época de aplicação do fluazifop-p-butil.

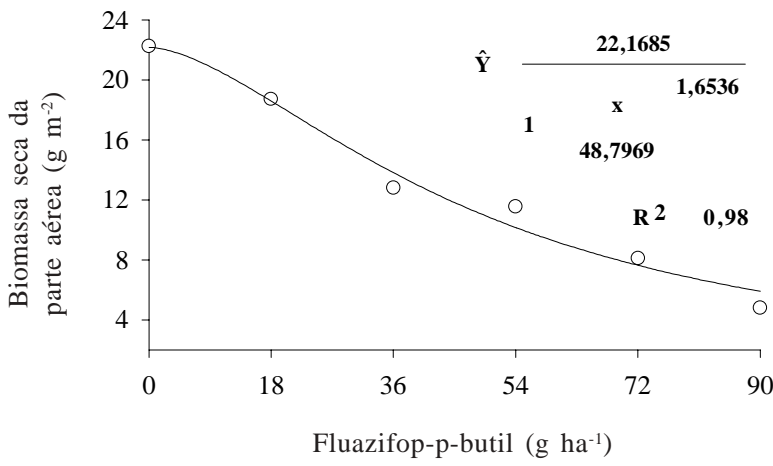

Figura 3 - Biomassa seca da parte aérea de B. brizantha, na colheita da soja, em função de doses de fluazifop-p-butil.

Observou-se apenas efeito de doses do fluazifop-p-butil sobre a altura das plantas de soja. No tratamento sem herbicida e na menor dose (tratamentos que permitiram maior acúmulo de biomassa da $B$. brizantha), as plantas apresentaram maior altura, evidenciando que o sombreamento promovido pela forrageira provocou o estiolamento da cultura. Isso pode ser observado pelo parâmetro "a" da equação de regressão (Figura 4-A), cujo valor é de $7,11 \mathrm{~cm}$ e representa a diferença entre a maior e a menor dose ou entre a ausência e presença de competição, respectivamente. $\mathrm{O}$ parâmetro $\mathrm{Y}_{0}$ da equação, cujo valor é de $68,72 \mathrm{~cm}$, corresponde ao limite inferior, ocorrido nas maiores doses, em que a forrageira exerceu baixa ou nenhuma interferência na cultura. Esse incremento em altura pode ser atribuído à procura por fatores necessários ao seu desenvolvimento, principalmente luz. Melges et al. (1989) verificaram que o sombreamento na cultura da soja causou incremento em altura nas plantas, devido ao maior alongamento dos entrenós e aumento da dominância apical. Segundo Ryle (1961), a dominância apical aumenta quando as plantas crescem sob baixos niveis de luz. Redfearn et al. (1999) observaram que, no consórcio entre sorgo e soja, a leguminosa mostrou alto grau de plasticidade morfológica, presumivelmente em resposta ao aumento da competição por luz, apresentando hastes mais finas e entrenós mais longos.

A altura de inserção da primeira vagem (AIV) foi influenciada pelas doses e épocas de aplicação do fluazifop-p-butil. Houve incremento na AIV quando não foi aplicado o herbicida e na menor dose, estabilizando-se a partir da dose de $36 \mathrm{~g} \mathrm{ha}^{-1}$ (Figura 4-B). De acordo com Durigan et al. (1983), a altura de inserção da vagem é dependente da eficiência fotossintética das folhas basais e, conseqüentemente, do transporte e da redistribuição de carboidratos para as regiões mais próximas desses pontos de elaboração da seiva.

Em relação à produção de grãos, observaram-se efeitos de doses e épocas de aplicação do fluazifop-p-butil. Verifica-se, pelo parâmetro "a" da equação de regressão (Figura 4-C), diferença na produção de $1,23 \mathrm{t} \mathrm{ha}^{-1}$ entre a maior e a menor dose do fluazifop-p-butil, evidenciando o potencial competitivo de $B$. brizantha e demais gramíneas infestantes. Houve maior produção de soja quando o herbicida foi aplicado aos 28 DAE, uma vez que a aplicação do fluazifop-p-butil uma semana antes (21 DAE) permitiu a reinfestação da área, o que contribuiu de forma significativa para a queda de produção. A produção da soja a partir das doses de $54 \mathrm{~g} \mathrm{ha}^{-1}$, aplicada aos $21 \mathrm{DAE}$, e de $36 \mathrm{~g} \mathrm{ha}^{-1}$, aplicada aos 28 DAE, não diferiu daquela da testemunha capinada, reforçando a importância do efeito da época de aplicação na produção da cultura. Duarte et al. (1995) verificaram, no consórcio das variedades de soja IAC-8 e Júpiter com B. brizantha, redução na produção de grãos de 52 e $40 \%$, respectivamente.

As variáveis estande final, número de sementes por vagem e peso de 100 sementes não foram afetadas pelos tratamentos. Esses resultados foram semelhantes aos observados por Chemale \& Fleck (1982). O componente de produção da soja mais influenciado 

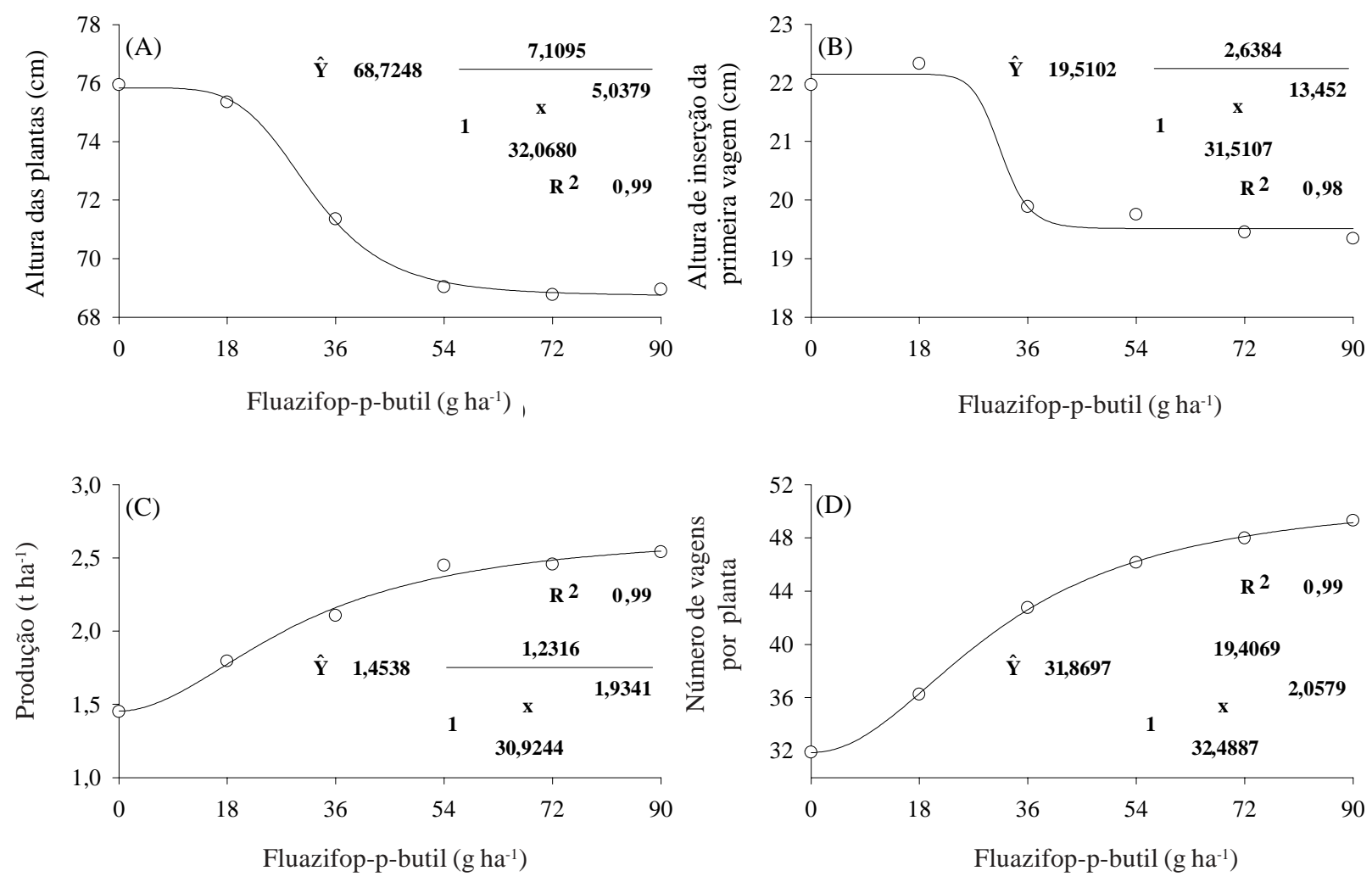

Figura 4 - Altura das plantas (A), altura de inserção da primeira vagem (B), produção de grãos (C) e número de vagens (D) de plantas de soja consorciada com B. brizantha, em função de doses de fluazifop-p-butil.

pela competição foi o número de vagens (Figura 4-D), o qual apresentou maior rendimento quando o herbicida foi aplicado aos 28 DAE. Jiang \& Egli (1993) verificaram que o sombreamento na cultura da soja reduz o número de vagens, devido ao aumento na abscisão de flores e vagens e ao menor número de flores por planta.

Nas equações de regressão apresentadas na Figura 4, pode ser visualizado que a altura das plantas e de inserção de primeira vagem, assim como a produção e o número de vagens por planta, apresentaram valor de $I_{50}$ semelhante, em torno de $31 \mathrm{~g} \mathrm{ha}^{-1}$, ou seja, foram influenciadas similarmente pela interferência da forrageira e das demais gramíneas.

Os resultados obtidos permitem concluir que é possível a viabilização do consórcio utilizando doses reduzidas de graminicida. Todavia, a presença de outras gramíneas na área pode inviabilizá-lo, visto que plantas como $B$. plantaginea, as quais apresentam rápido crescimento inicial, superam a forrageira rapidamente.

A época de aplicação correta é essencial no manejo de $B$. brizantha. A aplicação muito tardia, próxima ao fechamento da soja, pode não permitir a recuperação da forrageira devido ao sombreamento. No entanto, na aplicação precoce, pode ocorrer a emergência de novas plantas, que podem interferir na produção da cultura.

O incremento ou redução das doses promoveu queda do rendimento de $B$. brizantha e soja, respectivamente. Contudo, deve-se optar por uma dose intermediária que proporcione ganhos mútuos às espécies consorciadas.

\section{LITERATURA CITADA}

AMARAL, M. Plantio direto evolui no Brasil. Inf. Agropec., v. 22, n. 208, p. 3, 2001.

CARVALHO, S. I. C. et al. Recuperação de pastagens degradadas de Brachiaria decumbens cv. Basilisk na região dos Cerrados. Pasturas Trop., v. 12, n. 2, p. 24-28, 1990. 
CHEMALE, V. M.; FLECK, N. G. Avaliação de cultivares de soja (Glycine max (L.) Merrill) em competição com Euphorbia heterophylla L. sob três densidades e dois períodos de ocorrência. Planta Daninha, v. 2, p. 36-45, 1982.

COBUCCI, T. Manejo integrado de plantas daninhas em sistema de plantio direto. In: ZAMBOLIM, L. (Ed.) Manejo integrado fitossanidade: cultivo protegido, pivô central e plantio direto. Viçosa: UFV, 2001. p. 583-624.

DUARTE, J. M. et al. Producción de maíz (Zea mays L.), soya (Glycine max L.) y caupi (Vigna unguiculata (L.) Walp) sembrados en asociación con gramíneas en el trópico húmedo. Pasturas Trop., v. 17, n. 2, p. 12-19, 1995.

DURIGAN, J. C. et al. Períodos de matocompetição na cultura da soja (Glycine max (L.) Merrill), cultivares Santa Rosa e IAC-2. II - Efeitos sobre características morfológicas das plantas e constituição química dos grãos. Planta

Daninha, v. 6, n. 2, p. 101-114, 1983.

FEHR, W. R. et al. Stage of development descriptions for soybeans, Glycine $\max ($ L.) Merrill. Crop Sci., v. 11, p. 929-931, 1971.

FINNEY, D. J. Bioassay and the practice of statistical inference. Int. Stat. Rev., v. 47, n. 1, p. 1-12, 1979.

JIANG, H., J.; EGLI, D. B. Shade induced changes in flower and pod number and flower and fruit abscission in soybean. Agron. J., v. 85, p. 221-225, 1993.
KICHEL, A. N.; MIRANDA, C. H. B.; TAMBOSI, S. A. T. Produção de bovinos de corte com a integração agricultura $\mathrm{x}$ pecuária. In: SIMPÓSIO DE FORRAGICULTURA E PASTAGENS: TEMAS EM EVIDÊNCIAS, 1., 2000, Lavras. Anais... Lavras: UFLA, 2000. p. 51-68.

MELGES, E.; LOPES, N. F.; OLIVA, M. A.

Desenvolvimento e partição de assimilados em Glycine max crescida sob quatro densidades de fluxo radiante. Pesq. Agrop. Bras., v. 24, n. 9, p. 1081-1087, 1989.

PORTES, T. A. et al. Análise do crescimento de uma cultivar de braquiária em cultivo solteiro e consorciado com cereais.

Pesq. Agropec. Bras., v. 35, n. 7, p. 1349-1358, 2000.

REDFEARN, D. D.; BUXTON, D. R.; DEVINE, T. E. Sorghum intercropping effects on yield, morphology, and quality of forage soybean. Crop Sci., v. 39, n. 5, p. 1380-1384, 1999.

RYLE, G. J. A. Effects of light intensity on reproduction in S48 timoty (Phleum pratense L.). Nature, v. 19, p. 196197, 1961.

SALTON, J. C.; FABRÍCIO, A. M.; HERNANI, L. C. Integração lavoura-pecuária: alternativas de rotação de culturas. In: ENCONTRO REGIONAL DE PLANTIO DIRETO NO CERRADO, 5., 2001, Dourados. Anais... Dourados: UFMS/Embrapa CNPAO, 2001. p. 31-32 (Documentos, 31).

SEEFELDT, S.; JENSEN, J. E.; FUERST, E. P. Log-logistic analysis of herbicide dose-response relationships. Weed Technol., v. 9, n. 2, p. 218-227, 1995. 